\title{
Preparation of Myrica nagi (Box myrtle) drink and effect of storage temperature on its quality
}

\author{
Abhimanyu Thakur*, N. S. Thakur and Pradeep Kumar \\ 173230 (Himachal Pradesh), INDIA \\ *Corresponding author. E-mail: abhimanyuthakurprashar@gmail.com \\ Received: January 13, 2017; Revised received: May 1, 2017; Accepted: October 2, 2017
}

Department of Food Science and Technology, Dr. Y. S. Parmar University of Horticulture and Forestry, Nauni, Solan -

\begin{abstract}
Box myrtle (Myrica nagi) belongs to family Myricaceae is a sub-temperate tree found throughout the mid-Himalayas at an elevation of 1300 to 2100 meters above mean sea level. Its fruits are known for their ravishing taste and have been reported as rich source of anti-oxidants like phenols and anthocyanins. In the present study drink was prepared from box myrtle juice and quality evaluation was carried out during six months of storage of fruit drink. Different combinations of juice $(8 \%, 10 \%, 12 \%, 14 \%$ and $16 \%)$ and sugar syrup/TSS (Total soluble solids) $\left(12{ }^{\circ} \mathrm{B}\right.$ and $\left.15^{\circ} \mathrm{B}\right)$ were tried to standardize proper combination for drink. The drink prepared by following the best selected recipe (14\% juice and $12{ }^{\circ} \mathrm{B}$ TSS) was packed in glass and PET (Polyethylene terephthalate) bottles and stored for six months under ambient and refrigerated temperature conditions. Drink could be safely stored for a period of six months under both the storage conditions without much change in various quality characteristics. Various physico-chemical characteristics increased/decreased like TSS (12.05 to $\left.12.48{ }^{\circ} \mathrm{B}\right)$, reducing sugars (7.80 to $8.69 \%)$, titratable acidity ( 0.30 to $0.27 \%$ ), ascorbic acid $(1.09$ to $0.47 \mathrm{mg} / 100 \mathrm{~g})$, total phenols $(27.35$ to 19.11 $\mathrm{mg} / 100 \mathrm{~g}$ ) and anthocyanins $(6.14$ to $3.69 \mathrm{mg} / 100 \mathrm{~g})$. However, the changes in the quality characteristics of the drink were slower in refrigerated storage conditions as compared to ambient conditions. Both the packaging materials viz. PET and glass bottles were found suitable, with comparatively less changes occurring in glass bottles stored under refrigerated conditions.
\end{abstract}

Keywords: Box myrtle, Drink, Kaafal, Myrica nagi, PET, Storage

\section{INTRODUCTION}

Box myrtle (Myrica nagi) is a medium to large woody evergreen tree of genera Myrica in family Myricaceae and commonly known as kaafal in Himachal Pradesh. Myrica nagi tree is distributed in India, Nepal, China, Pakistan and Malaya Islands. The plant is commonly found in outer Himalayan region at an attitude starting from about 900 meters and going up to about 2100 meters. In India Myrica nagi is found from Punjab to Assam, including Arunachal Pradesh, Meghalaya, Nagaland, Manipur, Mizoram, Khasia, Sylhet, Himachal Pradesh, Jaintia, Shimla, Bengal, Naga and Lushai hills (Kumar and Rana, 2012).

The fruits of Myrica nagi are rich source of anti-oxidants along with other class of chemicals like flavanoids, saponins, tannins and unsaturated sterol/ triterpenes (Jeeva et al., 2011 and Kumar and Rana, 2012). Its fruits are known for their ravishing taste because of higher sugars, tannins and vitamin C (Jain and Jain, 2010 and Patel et al., 2011). The juice of this fruit is very attractive, sparkling red in colour and ripe fruits are consumed as a potential source of formulations for nutraceuticals (Saklani et al., 2012). The crop is highly perishable and susceptible to mechanical injury and physiological deterioration, resulting in a postharvest life of only 1 to 2 days under ambient temperature and 3-4 days at refrigerated conditions. Processing and value addition of fresh fruits is necessary, as the perishability rate is very high and harvesting period is very short. No work on processing of this fruit has been reported so far. So, being a rich source of antioxidants specially colour pigments like anthocyanins as well as sugars, this fruit can be exploited for the development of some beverages specially drink. Thus, the present studies were undertaken to develop drink from this fruit and study its storage life.

\section{MATERIALS AND METHODS}

The mature fruits of Myrica nagi were procured from Dumadevi area of Mandi district of Himachal Pradesh. Fruit drink was prepared by mixing known quantity of box myrtle juice in sugar syrup of different treatment combinations as given in Table 1 . To get the desirable concentration of acid $(0.30 \%)$ in drink, citric acid was added in different combinations. Sodium benzoate (120 ppm) was added at the end of product preparation of drink packed in PET bottles whereas drink packed in glass bottles was heat processed. The drink prepared by following the best selected recipe was packed in pre 
-sterilised glass (heat sterilized) and PET bottles (200 $\mathrm{ml}$ capacity). All the packed products were properly labelled and stored in ambient $\left(20-25{ }^{\circ} \mathrm{C}\right)$ and low temperature $\left(4-7^{\circ} \mathrm{C}\right)$ conditions for six months. Daily minimum and maximum ambient temperature was recorded and average values were taken throughout the study period. Low temperature conditions during storage were maintained in refrigerator. The physicochemical (colour, apparent viscosity, TSS, reducing sugars, titratable acidity, ascorbic acid, anthocyanins and total phenols) and sensory characteristics (colour, body, taste, aroma and overall acceptability) of all the products were estimated at zero, three and six months of storage. The colour of drink in terms of different units (Red and Yellow) was observed with Tintometer (Lovibond Tintometer Model-E). The apparent viscosity of the drink was determined by using Ostwald viscometer and was expressed in time (flow rate in seconds) taken for samples to pass through the tube. TSS, sugars, titratable acidity, ascorbic acid content and anthocyanins of drink were determined according to Ranganna (1997). Total phenols content was determined by Folin-Ciocalteu procedure given by Singeltonand Rossi (1965). Nine points hedonic rating test as given by Amerine et al. (1965) was followed for conducting the sensory evaluation of box myrtle drink. Data on physico-chemical characteristics of drink was analysed by Completely Randomized Design (CRD) before and during storage, whereas, data pertaining to the sensory evaluation were analyzed by using Randomized Block Design (RBD). The experiments on recipe standardization and for storage studies were replicated three times.

\section{RESULTS AND DISCUSSION}

Standardization of recipe for the preparation of box myrtle drink: Data on sensory characteristics of different recipes of box myrtle drink given in Table 2 indicated that the colour score was obtained highest (8.60) in $\mathrm{D}_{4}$ which was statistically at par with $\mathrm{D}_{5}$ and lowest (7.13) in $\mathrm{D}_{6}$ which was statistically at par with $\mathrm{D}_{7}$. The same recipe $\mathrm{D}_{4}$ obtained maximum body score of 8.40 which was statistically at par with $\mathrm{D}_{5}$ and minimum (7.03) in $\mathrm{D}_{1}$ and $\mathrm{D}_{2}$ which was statistically at par with $\mathrm{D}_{3}$ and $\mathrm{D}_{6}$. The highest score (8.23) of taste was also awarded to $\mathrm{D}_{4}$ while $\mathrm{D}_{10}$ got the lowest score of 5.60. The maximum (8.13) score for aroma was obtained in recipe $\mathrm{D}_{4}$ followed by $\mathrm{D}_{5}$ and minimum (7.60) in $\mathrm{D}_{2}$ followed by $\mathrm{D}_{6}$ and $\mathrm{D}_{9}$. The highest score (8.25) of overall acceptability was again in $\mathrm{D}_{4}$ closely followed by $\mathrm{D}_{5}$ and lowest score (7.15) in $\mathrm{D}_{10}$ closely followed by $\mathrm{D}_{9}$ and $\mathrm{D}_{8}$. The higher overall acceptability scores for recipe $\mathrm{D}_{4}$ might be due to better combination of juice-acid-syrup blend as compared to other recipes. From the Table 2 it was concluded that the recipe with 14 per cent juice and $12{ }^{\circ} \mathrm{B}$ TSS $\left(\mathrm{D}_{4}\right)$ was having highest sensory scores so considered as the best.

\section{Storage of box myrtle drink}

Physico-chemical characteristics

Colour: There was a significant decrease in red and yellow TCU (Tintometer Colour Units) of box myrtle drink during storage (Figure 1a and 1b). The reason for decrease in colour units of drink during storage might be due to degradation of anthocyanins pigment (De-Rosso and Mercadante, 2007). However, these pigments degraded at slower rate in low temperature hence less decrease observed in refrigerated conditions. Less decrease in colour units of drink packed in glass bottle than PET bottle observed because of slower rate of chemical reactions in product packed in glass bottle as a result of difference in their thermal conductance properties.

Apparent viscosity: Apparent viscosity of box myrtle drink in terms of flow rate increased (87 to 92.87

Table 1. Treatment combinations for the preparation of fruit drink.

\begin{tabular}{lcccccccccc}
\hline Treatment & $\mathbf{D}_{\mathbf{1}}$ & $\mathbf{D}_{\mathbf{2}}$ & $\mathbf{D}_{\mathbf{3}}$ & $\mathbf{D}_{\mathbf{4}}$ & $\mathbf{D}_{\mathbf{5}}$ & $\mathbf{D}_{\mathbf{6}}$ & $\mathbf{D}_{\mathbf{7}}$ & $\mathbf{D}_{\mathbf{8}}$ & $\mathbf{D}_{\mathbf{9}}$ & $\mathbf{D}_{\mathbf{1 0}}$ \\
\hline Juice $(\%)$ & 8 & 10 & 12 & 14 & 16 & 8 & 10 & 12 & 14 & 16 \\
TSS $\left({ }^{\circ} \mathrm{B}\right)$ & 12 & 12 & 12 & 12 & 12 & 15 & 15 & 15 & 15 & 15 \\
\hline
\end{tabular}

Table 2. Sensory characteristics (score) of different recipes of box myrtle drink.

\begin{tabular}{|c|c|c|c|c|c|}
\hline Treatment & Colour & Body & Taste & Aroma & Overall acceptability \\
\hline $\mathrm{D}_{1}$ & 7.47 & 7.03 & 7.27 & 7.70 & 7.38 \\
\hline $\mathrm{D}_{2}$ & 7.67 & 7.03 & 7.60 & 7.60 & 7.46 \\
\hline $\mathrm{D}_{3}$ & 7.83 & 7.13 & 7.73 & 7.80 & 7.61 \\
\hline $\mathrm{D}_{4}$ & 8.60 & 8.40 & 8.23 & 8.13 & 8.25 \\
\hline $\mathrm{D}_{5}$ & 8.47 & 8.27 & 7.73 & 7.93 & 7.97 \\
\hline $\mathrm{D}_{6}$ & 7.13 & 7.13 & 7.27 & 7.63 & 7.30 \\
\hline $\mathrm{D}_{7}$ & 7.33 & 7.27 & 6.90 & 7.83 & 7.33 \\
\hline $\mathrm{D}_{8}$ & 7.37 & 7.47 & 6.47 & 7.83 & 7.28 \\
\hline $\mathrm{D}_{9}$ & 7.47 & 7.43 & 6.33 & 7.63 & 7.23 \\
\hline $\mathrm{D}_{10}$ & 7.60 & 7.67 & 5.60 & 7.70 & 7.15 \\
\hline $\mathrm{CD}_{0.05}$ & 0.23 & 0.21 & 0.29 & 0.30 & 0.24 \\
\hline
\end{tabular}


Abhimanyu Thakur et al. / J. Appl. \& Nat. Sci. 9 (4): 2137 -2142 (2017)
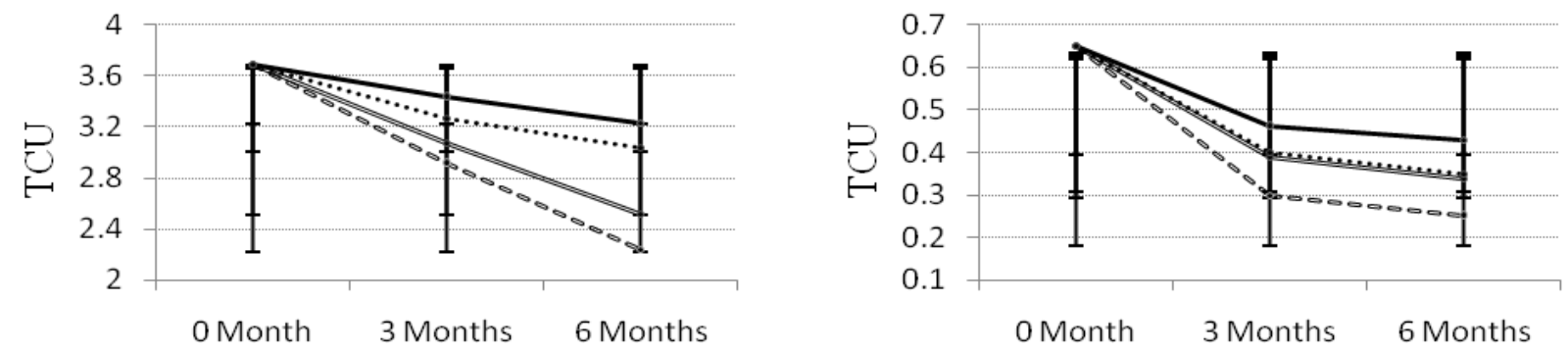

a. $\operatorname{Red} \mathrm{TCU}$

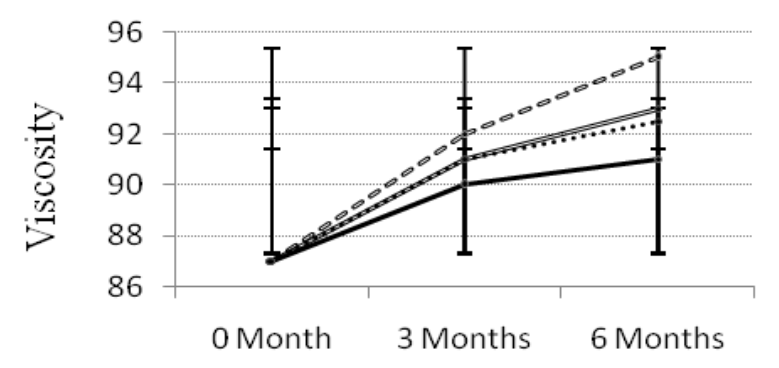

b. Yellow TCU

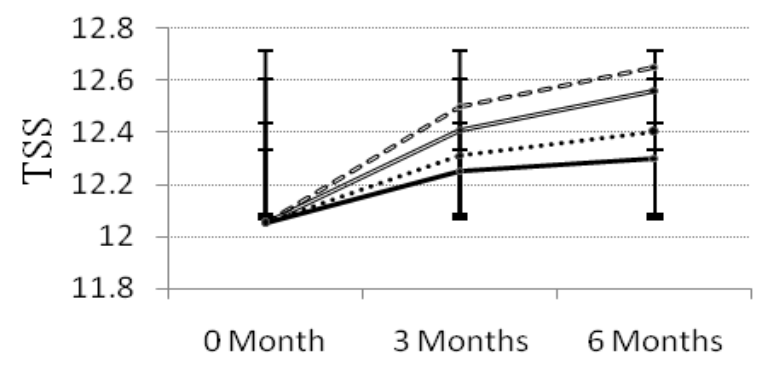

c. Apparent viscosity (Flow rate in seconds)

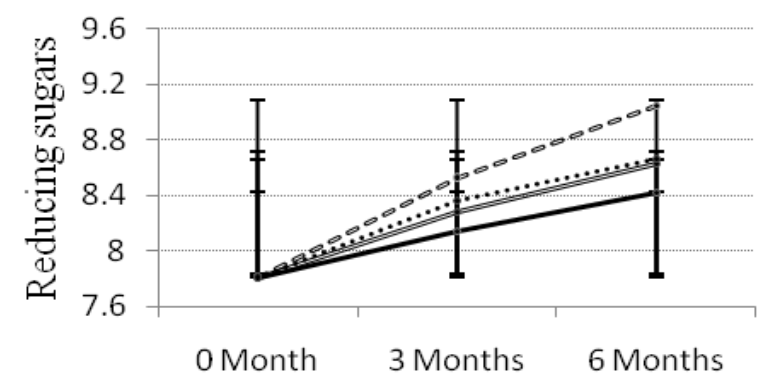

d. $\operatorname{TSS}\left({ }^{\circ} \mathrm{B}\right)$

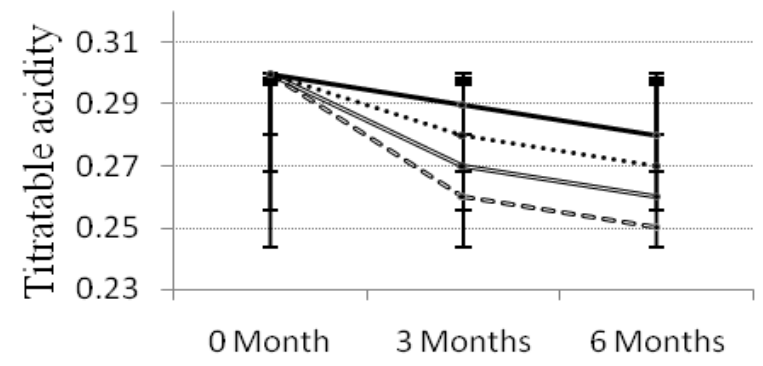

e. Reducing sugars (\%)

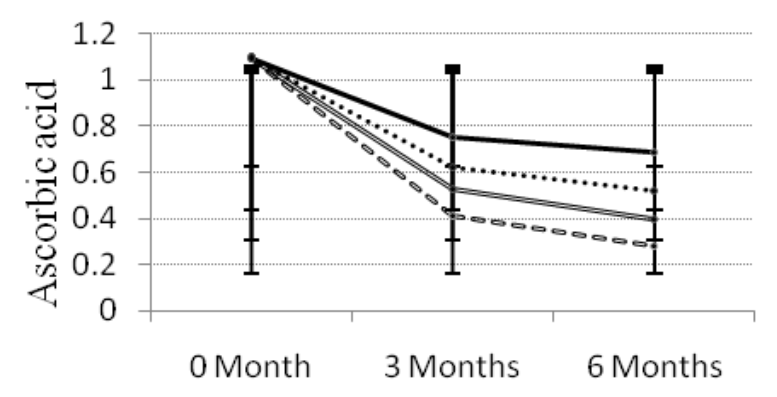

f. Titratable acidity (\%)

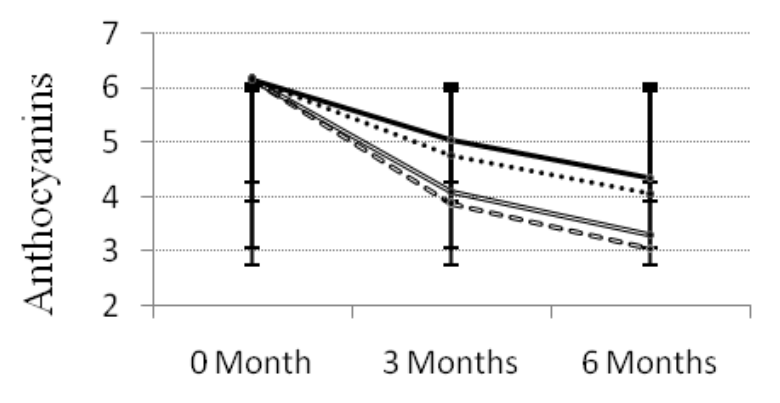

g. Ascorbic acid (mg/100 g)

h. Anthocyanins (mg/100 g)

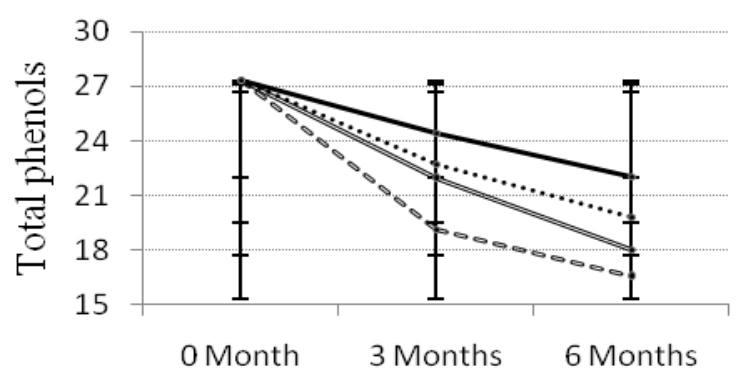

$\longrightarrow$ Ambient Glass

Ambient PET

—— Refrigerated Glass

Refirigerated PET

i. Total phenols $(\mathrm{mg} / 100 \mathrm{~g})$

Fig.1 (a-i). Effect of storage on physico-chemical characteristics of box myrtle drink 
seconds) significantly during the storage period (Figure 1c). However, overall effect of storage conditions shows that higher (90.83 seconds) viscosity in terms of flow rate was observed in ambient storage conditions as compared to refrigerated storage conditions (89.75 seconds). The apparent viscosity of the drink was at par in both the packaging materials as there was no significant difference among them. Increase in apparent viscosity may be due to the increase in TSS and soluble sugar which increased strain and shearing rate and decreased the flow index of the product. As the flow index decreased it helped to develop pseudo plasticity and increased the apparent viscosity (Bal et al., 2014). This increase in apparent viscosity was observed more in drink stored under ambient temperature conditions as compare to refrigerated storage conditions. However, as for the packaging material is concerned there was a non-significant difference in apparent viscosity of the drink. Similar results were reported by El-Mansy et al. (2005) in mango and papaya nectar.

TSS (Total soluble solids): There was a slight increase in TSS of box myrtle drink during storage (Figure 1d) which might be due to the hydrolysis of polysaccharides into monosaccharide and formation of invert sugar from sucrose. These results were in conformity with the findings of Mishra and Sangma (2017) in RTS (ready to serve) drink made from blend of Aloe vera, sweet lime, amla and ginger.

Reducing sugars: During storage of box myrtle drink, there was a gradual increase ( 7.80 to $8.69 \%$ ) in reducing sugars (Figure 1e). More increase in sugars was found in drink stored under ambient conditions (8.35 $\%)$ as compared to refrigerated storage conditions $(8.20 \%)$. The higher $(8.37 \%)$ reducing sugars were recorded in drink packed in PET bottle as compared to glass $(8.18 \%)$ bottle while comparing the overall effect of packaging materials on reducing sugars of drink. Sakhale et al. (2012) reported that the increase in reducing sugars might be due to the conversion of nonreducing sugars into reducing sugars in presence of citric acid. As far as the packaging material is concerned, more increase in sugars recorded in drink packed in PET bottle as compared to glass bottle might be due to faster rate of chemical reactions in the product packed in PET bottle as a result of their thermal conductance properties. Similar results were reported by Satkar et al. (2013) in bitter gourd RTS beverage and Priyanka et al. (2015) in jamun blended RTS beverages.

Titratable acidity: The titratable acidityof drink showed a slight decrease (0.30-0.27 per cent) during storage (Figure 1f), while with respect to storage conditions and packaging material this decrease was non-significant. Decrease in titratable acidity during storage might be due to co-polymerization of organic acids with sugars and amino acids. Our results were in conformity with the findings of Bisht et al. (2008) in seabuckthorn drink ( 0.30 to 0.25 per cent) and Kumar et al. (2010) in aonla-guava drink ( 0.27 to 0.20 per cent).

Ascorbic acid: There was a continuous decrease in ascorbic acid content of drink with advancement of storage period (Figure 1g) however; decrease was significantly lower under refrigerated conditions as compared to ambient conditions. Ascorbic acid content was retained higher $(0.79 \mathrm{mg} / 100 \mathrm{~g})$ in refrigerated conditions and lower $0.63 \mathrm{mg} / 100 \mathrm{~g}$ in ambient storage conditions. The more $(0.76 \mathrm{mg} / 100 \mathrm{~g})$ ascorbic acid was retained in glass bottle as compared to PET bottle $(0.67 \mathrm{mg} / 100 \mathrm{~g})$ during storage. Decrease in ascorbic acid content during storage might be due to its degradation into dehydro-ascorbic acid or furfural. Ascorbic acid is highly sensitive to heat; therefore its degradation was more in ambient conditions. Lower decrease in ascorbic acid of drink packed in glass bottle observed during storage might be due to the slower rate of reactions in it as glass materials absorb heat slower than PET material. Our results were in accordance with the findings of Vikram et al. (2016) in Kinnow-aonla RTS and Mishra and Sangma (2017) in RTS drink made from blend of Aloe vera, sweet lime, amla and ginger.

Anthocyanins: A significant decrease (6.14 to 3.39 $\mathrm{mg} / 100 \mathrm{~g}$ ) in anthocyanins content of drink was recorded during the storage (Figure 1h). The more retention of anthocyanins was observed $(5.08 \mathrm{mg} / 100$ g) in refrigerated storage conditions as compared to ambient conditions $(4.44 \mathrm{mg} / 100 \mathrm{~g})$. The higher (4.84 $\mathrm{mg} / 100 \mathrm{~g})$ anthocyanins content were recorded in drink packed in glass bottle and lower $(4.67 \mathrm{mg} / 100 \mathrm{~g})$ in PET bottle, while studying the overall effect of packaging materials on anthocyanins content of drink. Loss of anthocyanins in drink might be due to their high susceptibility to auto oxidative degradation during storage. More retention of this parameter in the product might be due to slower rate of auto oxidation of anthocyanins in the product under refrigerated storage conditions as compared to ambient. More retention of anthocyanins of drink packed in glass bottle during storage might be due to the slower rate of reactions in glass bottle than PET as a result of difference in their thermal conductance properties. Similar observations had been reported by Thakur et al. (2011) in wild pomegranate drink.

Total phenols: A gradual decrease in total phenols content of drink was observed during storage (Figure 1i), which was slower under refrigerated storage conditions than ambient conditions. Further, while comparing the overall effect of storage conditions it was found that more $(23.96 \mathrm{mg} / 100 \mathrm{~g})$ phenols were retained under refrigerated storage conditions as compared to ambient $(21.72 \mathrm{mg} / 100 \mathrm{~g})$ storage conditions. The overall effect of packaging materials indicates that more $(23.52 \mathrm{mg} / 100 \mathrm{~g})$ phenols were 


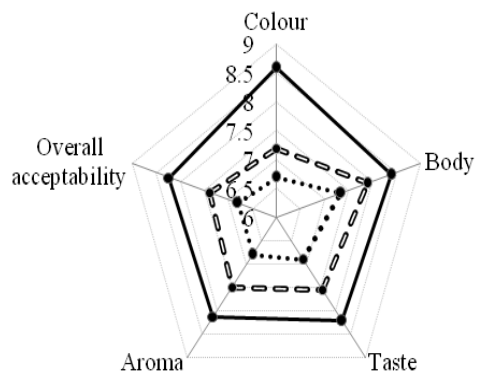

Fig. 2. Effect of storage on sensory characteristics of box myrtle drink packed in PET bottles stored under ambient conditions.
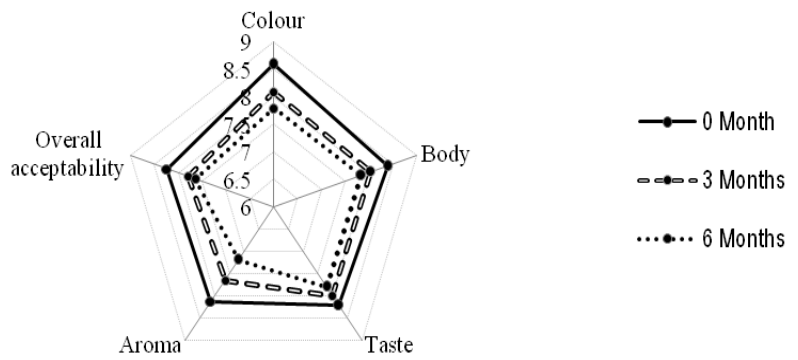

Fig. 4. Effect of storage on sensory characteristics of box myrtle drink packed in PET bottles stored under refrigerated conditions.

retained in glass bottle as compared to PET bottle $(22.16 \mathrm{mg} / 100 \mathrm{~g})$ during storage. Significant decrease in total phenol content during storage might be due to their involvement in the formation of polymeric compounds, complex formation of phenols with protein and their subsequent precipitations as observed in strawberry preserve by Abers and Wrolstad (1979). Slower rate of loss of phenols in refrigerated storage might be due to slower reaction rate in refrigerated conditions as compared to ambient. However, retention of more total phenols of drink in glass bottle may also be the slower reaction rates in glass bottle, as glass material absorb heat at slower rate as compared to PET. Similar observations were recorded byYadav et al. (2014) in guava-mango drink.

Sensory characteristics of box myrtle drink during storage: The colour, body, taste, aroma and overall acceptability scores of drink decreased significantly during storage (Figure 2-5) and this decrease was more pronounced under ambient storage conditionsthan refrigerated storage conditions. Retention of higher sensory scores in refrigerated conditions might be due to the better condition of the drink during storage as a result of slower rate of chemical reactions. Decrease in colour scores during storage might be due to degradation of colour pigment (anthocyanins) and browning caused by copolymerization of organic acids of the product and this might have led the judges to award the lower scores during storage. The possible reason for decrease in body scores might be due to the formation of

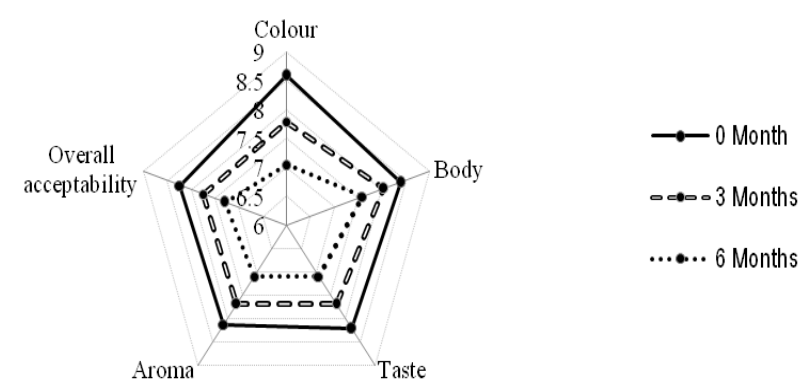

Fig. 3. Effect of storage on sensory characteristics of box myrtle drink packed in glass bottles stored under ambient conditions.

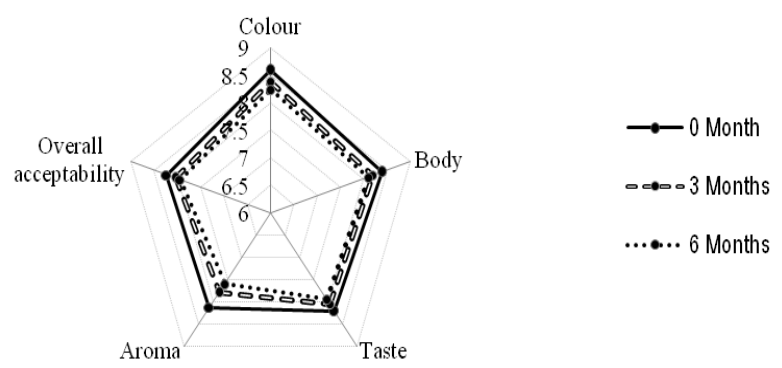

Fig. 5. Effect of storage on sensory characteristics of box myrtle drink packed in glass bottles stored under refrigerated conditions.

precipitates in the product as a result of interactions between phenols and protein as well as the formation of cation complexes with phenols during storage. The possible reason for decrease in taste scores might be due to the loss of sugar-acid blend responsible for taste during storage. The decrease in aroma scores during storage might be due to degradation of aromatic compounds in the product. There was a decrease in overall acceptability scores of drink during storage, which might be due to the loss in appearance, flavour compounds and uniformity of the product. Drink packed in glass bottles retained more sensory scores than PET bottles. The retention of better overall sensory scores of drink in glass bottles might be due to the better retention of above given factors as a result of slower reaction rate in glass bottles as compared to PET. The results were in conformity with the finding of Akhtar et al. (2013) in pomegranate drink, Vikram et al. (2016) in Kinnow-aonla RTS beverage and Mishra and Sangma (2017) in RTS drink made from blend of Aloe vera, sweet lime, amla and ginger.

\section{Conclusion}

The recipe with 14 per cent juice and $12{ }^{\circ} \mathrm{B}$ TSS $\left(D_{4}\right)$ was the best on the basis of sensory characteristics of the drink. Drink could be stored safely for a period of six months under both storage conditions and also in both packaging materials with minimum changes in chemical and sensory attributes. There was an increase in some physico-chemical parameters like viscosity 
(87 to 92.87 seconds) TSS (12.05 to $\left.12.48{ }^{\circ} \mathrm{B}\right)$, reducing sugars $(7.80$ to $8.69 \%)$ while titratable acidity $(0.30$ to $0.27 \%$ ), ascorbic acid (1.09 to $0.47 \mathrm{mg} / 100 \mathrm{~g}$ ), total phenols (27.35 to $19.11 \mathrm{mg} / 100 \mathrm{~g})$ and anthocyanins (6.14 to $3.69 \mathrm{mg} / 100 \mathrm{~g}$ ) decreased during storage. Various sensory characteristics scores of drink like colour (8.60 to 7.41$)$, body (8.40 to 7.73 ), taste (8.23 to 7.69$)$, aroma (8.13 to 7.18$)$ and overall acceptability (8.24 to 7.39) decreased during storage. However, comparatively fewer changes in drink packed in glass bottle and stored under refrigerated storage conditions were observed as compared to PET bottle.

\section{REFERENCES}

Abers, J.E. and Wrolstad, R.E. (1979). Causative factors of colour determination in strawberry preserve during processing and storage. Journal of Food Science and Technology44:75-81.

Akhtar, S., Ali, J., Javed, B. and Khan, F.A. (2013). Studies on the preparation and storage stability of pomegranate juice based drink. Middle-East Journal of Scientific Research 16(2):191-195.

Amerine, M.A., Pangborn, R.M. and Roessler, E.B. (1965). Principles of sensory evaluation of food. Academic Press: London.

Bal, L.M., Ahmad, T., Senapati, A.K. and Pandit P.S. (2014). Evaluation of quality attributes during storage of guava nectar cv. Lalit from different pulp and TSS ratio. Food Processing and Technology 5(5):349-353.

Bisht, R., Sharma, S.K. and Yadav, V.K. (2008). Studies on preparation and storage evaluation of seabuckthorn (Hippophae salicifolia D. Don.) ready-to-serve beverage. Asian Journal of Horticulture 3(1):117-121.

De-Rosso, V.V. and Mercadante, A.Z. (2007). Evaluation of colour and stability of anthocyanins from tropical fruits in an isotonic soft drink system. Innovative Food Science and Emerging Technologies 8: 347-352.

El-Mansy, H.A., Sharoba, A.M., Bahlol, H.E.M. and El-Desouky, A.I. (2005). Rheological properties of mango and papaya nectar. Annals Agric Sci Moshtohor 43:665-686.

Jain, V.K. and Jain, B. (2010). Anthihelmintic activity of ethanolic extract of bark of Myrica esculenta. Journal of Pharmaceutical Science 1:129-131.

Jeeva, S., Lyndem, F.G., Sawian, J.T., Laloo, R.C. and Mishra B.P. (2011). Myrica esculenta - a potential ethnomedicinalspecies in a subtropical forest of Meghalaya, Northeast India.Asian Pacific Journal Tropical Biome 2:174-177.
Kumar, K and Rana, A.C. (2012). Pharmacognostic and pharmacological profile of traditional medicinal plant: Myrica nagi. International Research of Pharmacy 3 (12): 32-37.

Kumar, S., Godara, R.K., Sharma, R.K. and Kumar, S. (2010). Quality evaluation of ready-to-serve (RTS) from different blends of aonla. Haryana Journal of Horticulture Science 39(3-4):260-262.

Mishra, L.K. and Sangma, D. (2017). Quality attributes, phytochemical profile and storage stability studies of functional ready to serve (RTS) drink made from blend of Aloe vera, sweet lime, amla and ginger. Journal of Food Science and Technology 54(3): 761-769.

Patel, T., Dudhpejjya, A. and Sheath, N. (2011). Anti inflammatory activity of Myrica nagi Linn. Bark. Ancient Science Life 30:100-103.

Priyanka, N., Dorajeerao, A.V.D. and Sudhavani, V. (2015). Utilisation of jamun juice by making blended RTS beverages. Plant archives 15(2): 1083-1088

Ranganna, S. (1997). Handbook of analysis and quality control for fruit and vegetable products. Tata McGraw Hill, New Delhi.

Sakhale, B. K., Pawar, V.N. and Ranveer, R. C. (2012). Studies on development of soymilk based mango RTS beverage. Electronic Journal of Environmental, Agricultural and Food Chemistry 11(5): 523-528.

Saklani, S., Chandra, S., Mishra, A.P. and Badoni, P.P. (2012). Nutritional evaluation, antimicrobial activity and phytochemical screening of wild edible fruit of Myrica nagi pulp. International Journal of pharmacy and Pharmaceutical Sciences 4:407-411.

Satkar, K.P., Kulthe, A.A. and Chalke, P.R. (2013). Preparation of bitter gourd ready-to-serve beverage and effect of storage temperature on its keeping quality. Bioscan 8 (1):115-117.

Singelton, V.L. and Rossi, J.A. (1965). Colorimetry of total phenolics with phosphomolybedicphosphotungstic acid reagent. American Journal of Enology and Viticulture 16:144-158

Thakur, N.S., Dhaygude, G.S. and Joshi, V.K. (2011). Development of wild pomegranate drink and its evaluation during storage. International Journal of Food and Fermentation Technology 1(2): 237-246.

Vikram B., Prasad, V.M. and Narayan, S. (2016). Studies on Kinnow-aonla ready-to-serve beverages. Indian Journal of Horticulture 73(2): 308-311.

Yadav, S., Gehlot, R., Siddiqui, S. and Grewal, R.B. (2014). Changes in chemical constituents and overall acceptability of guava-mango Ready-to-Serve (RTS) drink and squash. Beverage and Food World 41(4):3033. 